ISAHP 2001, Berne, Switzerland, August 2-4, 2001

\title{
CONSENSUS WITH THE ANALYTIC HIERARCHY PROCESS AT DAR AL HEKMA, SAUDI ARABIA
}

\author{
Asma M. A. Bahurmoz \\ Dar Al Hekma College \\ P.O. Box 9550, Jeddah 21423, Saudi Arabia \\ e-mail: Bahurmoz@kaau.edu.sa
}

Keywords: AHP, group decision making, scholarship, Saudi Arabia.

Summary: I designed and implemented a multicriteria group decision-making model based on the Analytic Hierarchy Process to select the best candidates to send overseas for graduate studies, eventually becoming teachers at the newly created Dar Al-Hekma women's college in Jeddah, Saudi Arabia. The paper highlights the model together with the challenges involved in making a scientific application of an OR method that proves to be robust in a highly political environment. Its application does not require from the user an understanding of the sophisticated albeit transparent theory that underlies the methodology. It is user friendly and involves simple constructions in conformity with what people actually do using logic and discussion to express their opinions in a collective effort to make a decision. Its outcome creates public trust in the management of the college.

\section{Dar Al-Hekma College}

Until 1998, the Ministry of Higher Education (MOHE) was the only authority in Saudi Arabia that was responsible for higher education. Education is provided free of charge in Saudi Arabia. Enrolled students are paid a monthly allowance until they graduate. However, as demand for higher education exceeds the capacity of public universities and other public colleges, MOHE is now giving permission to the private sector to provide higher education through non-profit organizations.

Dar Al-Hekma is one of the first private colleges for women that began under the new system. It entered its second year of operation in August 2000. Located in Jeddah, The College offers a four-year baccalaureate program and associate degrees in Business Information Systems, Interior Design, and Special Education. All courses are taught in English with the exception of Arabic and Islamic Studies.

This new college is facing several challenges involving a need for rational decision-making. The problem of shortage of qualified women to staff the three departments is only one such problem. Recruiting from the USA could be an option, but it is not a viable long-term solution. One way to solve the staffing problem is to send Saudi women to be trained abroad. To help Dar Al-Hekma carry out this policy MOHE is offering nine scholarships for graduate studies in the USA and the UK. Who to select? 


\section{THE PROBLEM}

The board of trustees asked the academic committee to select nine candidates. The committee consisted of seven members, four experienced faculty members from local public universities, acting as external consultants, plus three members of the board of trustees.

During the first meeting the committee established that their objective was to select nine qualified women who are interested in continuing their graduate studies abroad and in one of the three majors the college needs most. More than one strategy was suggested for choosing the candidates. Many hard questions that focused on measurable and non-measurable issues were posed. Should the committee give priority to those who are committed to become teachers over those who are already studying abroad who may not have expressed such interest prior to this? How does the committee trade off a high grade point average (GPA) against a low TOEFL's score? Is the applicant suitable for a faculty position, which is the main purpose for financing her education abroad? The answers to these questions are not straightforward ones. They depend on the judgments, preferences and goals of the academic committee, which in turn reflect those of the board of trustees and the administration. The debate went on for two meetings without any agreement reached regarding the process of selection, not to mention the heated conversations that were carried over outside the meeting room.

\section{THE WAY OUT}

Many Saudi women today are willing to travel abroad to pursue their schooling and their families will support such a decision, unlike in the past. So, the number of applicants is expected to be large and the selection process will be very competitive, without even mentioning the politics and social pressure that the committee will face during the process. Such an environment could end up in an unfair, non-objective selection that would not be to the benefit of the college. It is important for a new college to be perceived as being unbiased. More to the point, the need for the selection process is expected to be repeated every time a decision is required to award more scholarships, or grants to undergraduate students, etc.

As a member of the committee and the newly appointed permanent provost, I proposed the application of a scientific decision making model that would help the committee to carry out the selection process in a fair, objective and effective way. It has been fortunate for me to be the first woman in my country to have obtained my Ph.D. training in operations research at imperial College, London. The mathematics I learned has served well to solve this and other problems in a country where decisions are made in very traditional ways.

A sub-committee emerged from the academic committee consisting of four members including the author as the chairman of the committee to develop the model and apply it to the selection problem.

\section{The Selection Model}

The problem as described above is a multicriteria decision. It can also be described as a group decisionmaking problem. The methodology that lends itself very easily is the rating model of The Analytic 
Hierarchy Process (AHP)[Saaty, 1980]. AHP provides the objective mathematics to process the inescapably subjective and personal preferences of an individual or a group in making a decision. It involves constructing a hierarchy, then making judgments or performing measurements on pairs of elements with respect to a controlling element to derive ratio scales that are then synthesized throughout the structure to select the best alternative. Since the number of applicants is more than nine candidates we opt to the rating version of the AHP. (Saaty, 1996) In what follows these steps are applied to our problem.

\section{Constructing the hierarchy}

This is the most important phase of designing the selection model. The first step is to clearly state the objective of the selection process.

The committee agreed that the goal is to select the best nine qualified applicants to study abroad and return to work for Dar Al Hekma as faculty members. Over two consecutive meetings the committee developed the criteria necessary to achieve the stated goal.

Applicants will be evaluated on two sets of criteria: qualitative and quantitative. These two types of criteria will make up the second level of the hierarchy. In level three, each of the above two clusters is decomposed into several sub-criteria. (Figure 1).

The qualitative cluster is divided into: personality tests, work experience, and other information provided by the applicant:

I- the personality tests are of two types:

1- Personality analytical test: all applicants sit at the same time for a written personality analysis test that will indicate the applicant's professional skills and her potential to grow professionally. This test is supplemented by a personal interview conducted by a career consultant. Results are rated as: high potential, good potential, medium potential and poor potential.

2- Academic interview: the sub-committee interviews applicants individually. The purpose of the interview is to confirm the suitability of the applicant for the teaching job and readiness to travel abroad. The outcome is rated as: outstanding, excellent, very good, good, and poor.

II- Work experience is subdivided into two sub-criteria:

1- Years of experience: Applicants are rated as having more than four years of experience, two to four years, less than two to one year and less than one year.

2- Type of experience: Applicant's experience is classified into four categories: teaching at college level, teaching at pre-college level, administrative and other type of work.

III- other information is classified into:

1- Letters of recommendation.

2- Extra curricula activities.

Member of the committee will examine each of these two items. The first item is categorized into excellent, good and none, that is, the applicant did not provide recommendation letters and the second item is rated as outstanding, excellent, very good, good and none, which means that the applicant has no activities at all while she was a student. 


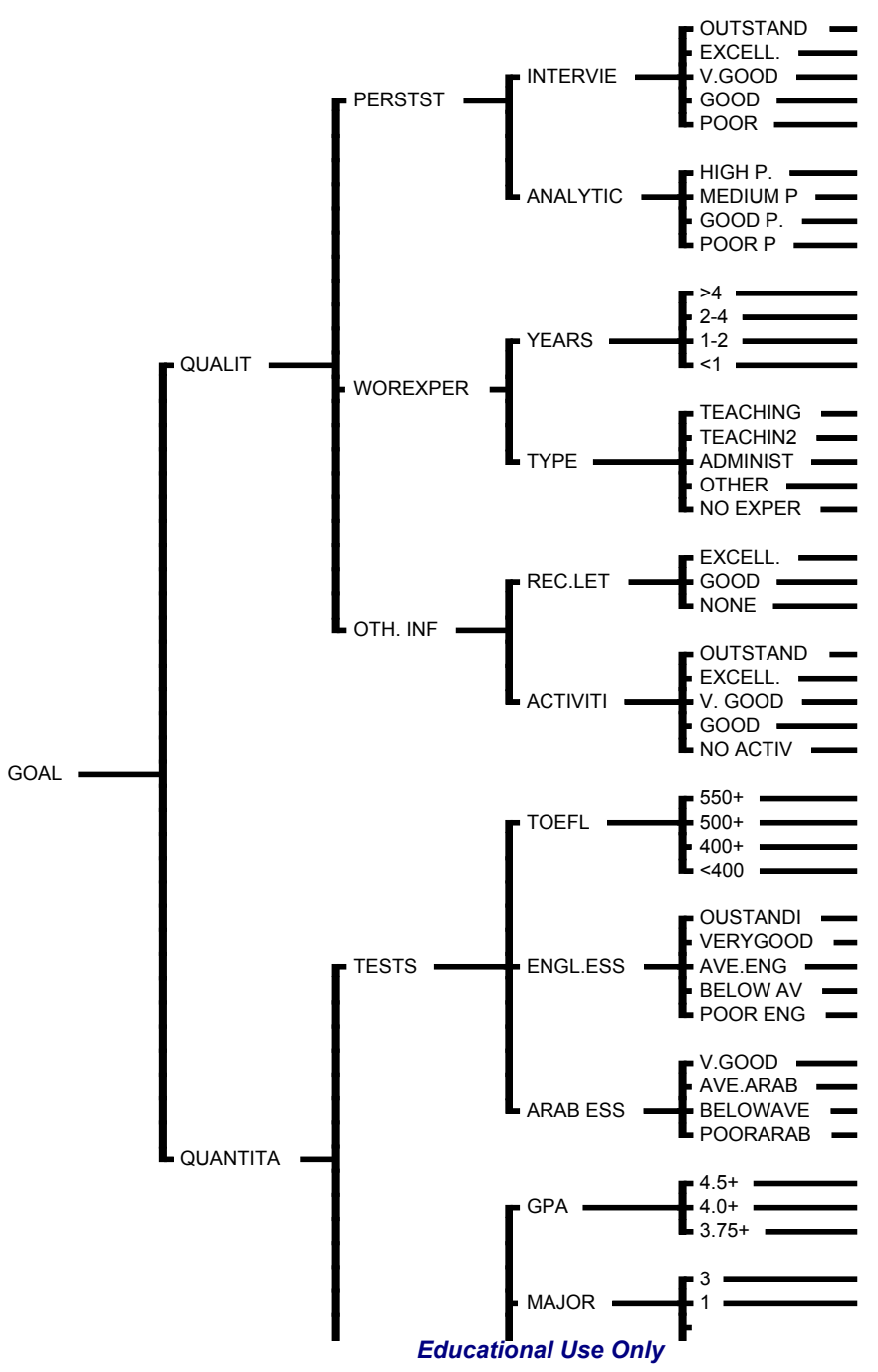

Figure 1: This is the hierarchy that was developed by the committee to represent the levels of the criteria, sub criteria and the intensities, which used in the rating of the AHP model

The quantitative cluster is divided into two sub-criteria:

I. Language tests: Students sit for three types of language tests:

1-TOEFL: This is an old version of the paper-based test. Applicants are classified into four categories according to their scores, $550+, 550$ up 499, 500 up to 400, and less than 400 .

2- English essay: applicants are required to write about 800 words within one hour on one of three topics which involve statement of purpose. These essays are blindly marked by a faculty member in terms of: content, style, grammar and general writing ability. Then ranges of marks are categorized as outstanding, very good, average, below average and poor. 
3- Arabic essay: applicants were required to go through similar procedure as the one for English; however, essay topics are to reflect the applicant's attitude towards religion, national identity, and teaching profession.

II. Information on previous degree/s. This criterion is broken into four sub-criteria:

1- GPA: is the actual average from final degree work that is shown on an applicant's official transcript. The ratings for GPA are divided into four categories (4.5 or more, 4.0-less than 4.5, 3.5-less than 4, 3.0- less than 3.5.) Applicants who score less than three were excluded from the selection process at an early stage.

2- Major: applicants from different fields were invited to apply to the three fields into which they will continue their graduate study. Graduates of computer science, math, business and college of administration and economics graduates will be considered to join the department of Business Information Systems. Graduates of interior design, housing, home economics and education will be considered for the department of interior design. Graduates of special education, physiology on sociology will be considered to study special education. However, the four fields will be rated according to their relevance to the department they will join on returning.

3- Ranking of the university awarding the degree. Applicants are classified into two categories, local or foreign university. It would be easier for a foreign university graduate to continue studying overseas.

4-Masters degree: The fact that some applicants have already begun their graduate studies at a local university reflects their ambition and desire for knowledge. The committee thought that it would be essential to differentiate between those who are already in such programs and those who are not. Hence this criterion is divided into three categories:

1) Thesis: means the student has finished course work and is working on her thesis.

2) Course: the applicant has not finished the courses.

3) None: the applicant has not started a Masters program.

\section{Establishing the Priorities}

The sub-committee judged the importance of the criteria, sub-criteria and the intensities in a four-hour session. Team Expert Choice, a computerized package was used to do the mathematical calculations of the priorities. Each member of the committee gave her judgment, one at a time; then the geometric mean was calculated and reviewed at every level. For example see Figure 2 and Figure 3. Finally the global priorities of the criteria were calculated and results are shown in Figure 4.

Next, the committee compared the performance rating at the bottom level of the hierarchy (the intensities). Experts outside the committee determined the priorities of some of these intensities (Figure 5). Once the overall weights were generated, individual applicants were rated. This was done using a Lotus spread sheet with table look-up functions to carry out the rating process. 
Compare the relative IMPORTANCE with respect to: QUALIT \& GOAL

\begin{tabular}{|c|c|c|}
\hline & WOREXPER & OTH. INF \\
\hline PERSTST & 1.5 & 5.0 \\
\hline WOREXPER & & 4.0 \\
\hline
\end{tabular}

\begin{tabular}{|l|l|}
\hline \multicolumn{1}{|c|}{ Abbreviation } & \multicolumn{1}{c|}{ Definition } \\
\hline Goal & Select the best nine candidates for scholarships abroad \\
\hline QUALIT & Qualitatve criterion : personality tests \& applic. information \\
\hline PERSTST & This includes personality analytical tests and interviews. \\
\hline WOREXPER & Work experience the applicant has since graduation. \\
\hline OTH. INF & RECOMMENDATION LETTERS\& ACTIVITIES WHILE AT COLLEGE \\
\hline
\end{tabular}

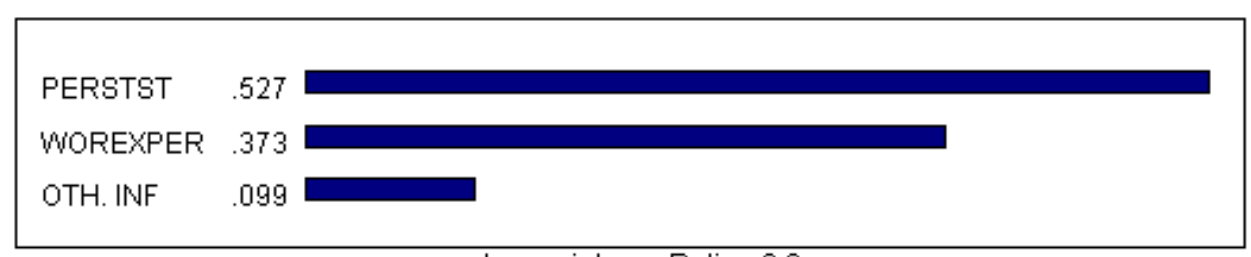

Inconsistency Ratio $=0.0$

Figure 2: The pair wise comparison matrix of the qualitative criteria. The diagram below shows the relative importance the committee gave to each sub criteria with respect to the qualitative criteria 
Node: 22000

Compare the relative MMPORTANCE with respect to: DEGREE $<$ QUANTITA \& GOAL

\begin{tabular}{|c|c|c|c|}
\hline & MAJOR & UAD & MASTER \\
\hline GPA & $(1.9)$ & 2.2 & 1.2 \\
\hline MAJOR & & 4.2 & $(2.0)$ \\
\hline UAD & & & $(3.0)$ \\
\hline
\end{tabular}

\begin{tabular}{|l|l|}
\hline \multicolumn{1}{|c|}{ abbreviation } & \multicolumn{1}{c|}{ Definition } \\
\hline Goal & Select the best nine candidates for scholarships abroad \\
\hline QUANTITA, & Quantitative criterion: Language tests \& degree information \\
\hline DEGREE & University degree: GPA, Major, Master?? \\
\hline GPA & Grade Point Average \\
\hline MA,JOR & Major of the latest degree the student has. \\
\hline UAD & UNIVIVRSITY AWMARDED THE DGREE \\
\hline MASTER & STARTED MASTERS PROGRAM \\
\hline
\end{tabular}

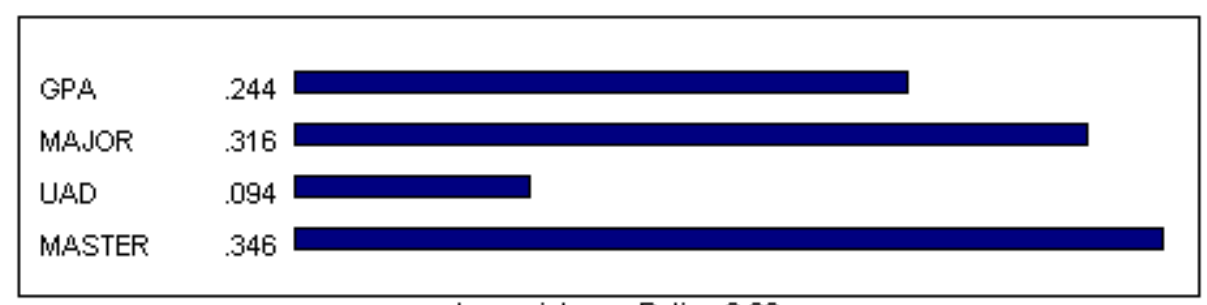

Inconsistency Ratio $=0.08$

Figure 3: The pair wise comparison matrix of the sub criteria of the degree the applicant has as one of the quantitative criteria. The diagram below shows the relative importance the committee gave to each sub criteria with respect to the degree the applicant has 


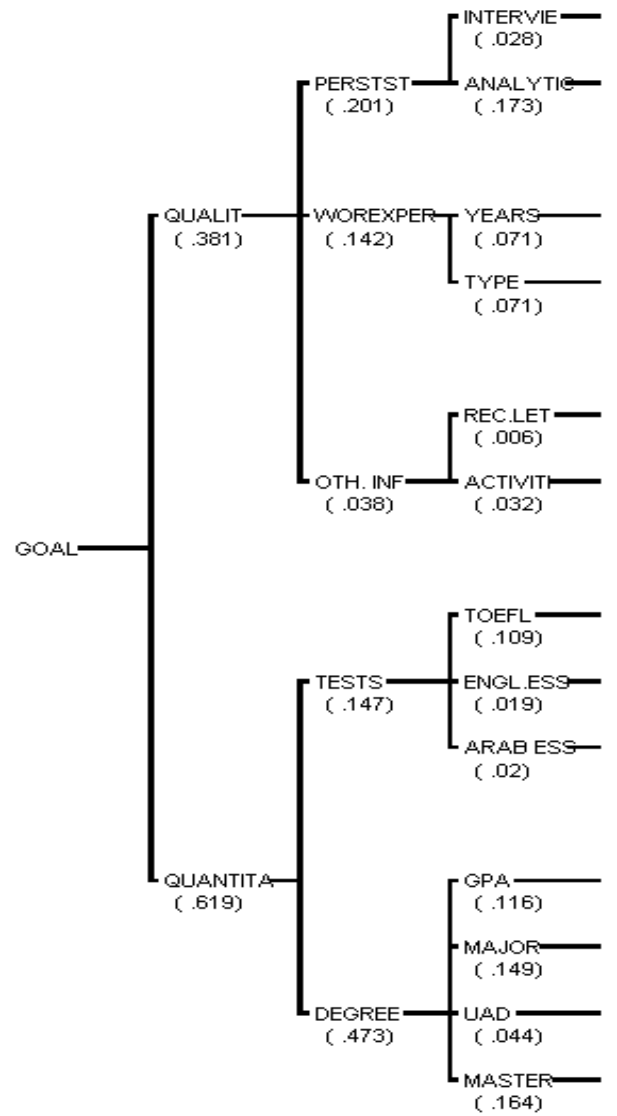

Figure4: The Analytic Hierarchy for selecting the best nine candidates. Global priorities of each criterion are shown in brackets 
SELECT THE BEST NINE CANDIDATES FOR SCHOLARSHIPS ABROAD

Node: 22100

Compare the relative PREFERENCE with respect to: GPA < DEGREE < QUANTITA < GOAL

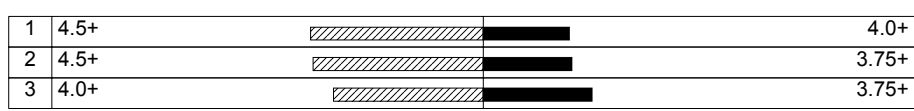

\begin{tabular}{|l|l|}
\hline \multicolumn{1}{|c|}{ Abbreviation } & \multicolumn{1}{c|}{ Definition } \\
\hline Goal & $\begin{array}{l}\text { SELECT THE BEST NINE CANDIDATES FOR SCHOLARSHIPS } \\
\text { ABROAD }\end{array}$ \\
\hline QUANTITA & Quantitative criterion: Language tests \& degree information \\
\hline DEGREE & UNIVERSITY DEGREE: GPA, MA: GPA, MAJOR, MASTER?? \\
\hline GPA & GRADE POINT AVERAGE \\
\hline $4.5+$ & GPA $=4.5$ UP TO 5.00 \\
\hline $4.0^{+}$ & GPA $=4.00$ UP TO LESS THAN 4.5 \\
\hline $3.75+$ & GPA $=3.75$ UP TO LESS THAN 4.00 \\
\hline
\end{tabular}

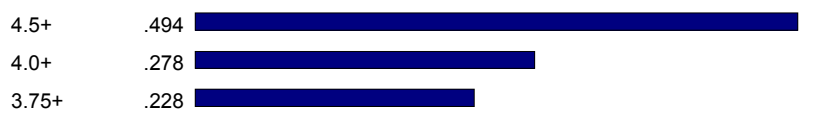

Inconsistency Ratio $=0.01$

Educational Use Only

Figure 5: Comparing intensities of the GPA 


\section{Conclusions}

The AHP model helped the committee to make a complex selection decision. The process ensured that committee members are in general agreement with the goal to select the best nine candidates. The model is systematic and comprehensive. It effectively includes all the criteria the committee wished to include. The advantages of the model were:

1. Fairness to the applicants: it provides for consistent decision-making. All applicants were subjected to a single set of weighted criteria that reduced the subjectivity of the selection process. Such an approach improves the social image of Dar Al Hekma.

2. The AHP model also provides a systematic framework for the committee interaction and decisionmaking. Members have the opportunity to interact, to debate, justify and modify their personal judgments. A few differences of opinion proved not to have a significant impact on the selection process. The AHP offers an opportunity to represent various interests in a balanced participation.

3.The model saved time and personal relationships in such a way the management of the college recommended to extend the application of the methodology to all other area that involve decision making; e.g., selection of recipients for internal grants. This is another sensitive area for the college's image and is a recurring issue at the beginning of each semester.

\section{References}

Carlsson, C. \& Pirkko Walden (1995) " AHP in Political Group Decisions: A study in the Art of Possibilities", Interfaces 25, no. 4, (14-29).

Liberatore, M. J., Nydick, R. L. \& Sanchez, P. M., (1992) "The Evaluation of Research Papers (or How to Get an Academic Committee to Agree on Something)", Interfaces, Vol. 22, No. 2: (92-100)

Saaty, T. (1996) "Decision Making For Leaders: The Analytic Hierarchy Process For Decisions In A Complex World", RWS Publication.

Schniederjans, M \& Tim Garvin (1997) “ Using the Analytical Hierarchy Process”, EJOR, vol.100, no.1 (72-80).

Vergas, L.G. (1990) “An Overview of the Analytic Hierarchy Process and Its Application”, European Journal of Operational Research, Vol.48, no1, (2-8).

Zahidi, F., (1985) "The Analytic Hierarchy Process- A Survey of the Method and Its Application", Interface vol.16, no. 4, (96-108).

Asma Bahurmoz has a Ph D in OR from Imperial College for Science, Technology and Medicine, The University of London. She is an associate professor at King Abdul Aziz University and the Dean of Dar AlHekma private college in Saudi Arabia. Her research and activities concentrated on introducing and applying OR methods in the educational and health sector in Saudi Arabia. 